\section{RMD Open}

Rheumatic \&

Musculoskeletal Diseases

\title{
Spondyloarthritis in inflammatory bowel disease cohorts: systematic literature review and critical appraisal of study designs
}

\author{
Monica Schwartzman (D) , ${ }^{1}$ Joerg Ermann, ${ }^{2}$ Kristine A Kuhn, ${ }^{3}$ \\ Sergio Schwartzman, ${ }^{4}$ Michael H Weisman ${ }^{5}$
}

To cite: Schwartzman M, Ermann J, Kuhn KA, et al. Spondyloarthritis in inflammatory bowel disease cohorts: systematic literature review and critical appraisal of study designs. RMD Open 2022;8:e001777. doi:10.1136/ rmdopen-2021-001777

- Additional supplemental material is published online only. To view, please visit the journal online (http://dx.doi.org/10. 1136/rmdopen-2021-001777).

Received 14 June 2021 Accepted 2 November 2021
Check for updates

(c) Author(s) (or their employer(s)) 2022. Re-use permitted under CC BY-NC. No commercial re-use. See rights and permissions. Published by BMJ.

For numbered affiliations see end of article.

Correspondence to Dr Monica Schwartzman; schwartzmanm@hss.edu

\section{ABSTRACT}

To critically appraise study designs evaluating spondyloarthritis $(\mathrm{SpA})$ phenotypes in patients with inflammatory bowel disease (IBD). A systematic literature review of PubMed, Ovid, Scopus, Cinahl, Medline, Web of Science, and Cochrane databases was performed. Articles published from January 2000 - March 2020 were included if they evaluated the prevalence/incidence of musculoskeletal disease in cohorts of IBD patients. Most of the 69 included studies were clinic based $(54 / 69,78 \%)$, single center $(47 / 69,68 \%)$ and cross-sectional $(60 / 69$, $87 \%$ ). The median prevalence of axial and peripheral SpA in IBD was $5 \%$ (range 1 - 46\%) and 16\% (range 1 - 43\%), respectively. In 38 studies that evaluated axial disease in prospectively enrolled patients, inflammatory back pain was analyzed in $53 \%$. SpA classification criteria were used in $68 \%$ and imaging was performed in $76 \%$. In 35 studies that evaluated peripheral disease in prospectively enrolled patients, SpA classification criteria were used in $46 \%$. A physical exam was performed in $74 \%$, and it was performed by a rheumatologist in $54 \%$ of studies with a physical exam. Sub-phenotypes of peripheral SpA (monoor oligo-arthritis, polyarthritis, enthesitis, dactylitis) were variably reported. Seventy-four percent of studies did not mention whether osteoarthritis and fibromyalgia had been assessed or excluded. The spectrum of SpA phenotypes in IBD patients remains incompletely characterized. Future studies should focus on standardizing the variables collected in IBD-SpA cohorts and defining musculoskeletal phenotypes in IBD-SpA in order to better characterize this disease entity and advance the field for clinical and research purposes.

\section{INTRODUCTION}

Inflammatory bowel disease (IBD), which includes ulcerative colitis (UC) and Crohn's disease $(\mathrm{CD})$, is a chronic inflammatory illness of the gastrointestinal tract associated with various extraintestinal manifestations (EIMs) of which rheumatologic manifestations, which include peripheral and axial spondyloarthritis (SpA), are the most common. The

\section{Key messages}

Despite the prevalence of spondyloarthritis $(\mathrm{SpA})$ in inflammatory bowel disease (IBD), it remains under recognised and understudied in both gastroenterology and rheumatology.

Multiple IBD-SpA cohorts exist, however, overall IBDSpA cohorts remain very heterogeneous with varying trial designs, evaluation protocols and outcome measures.

- Attempts at the identification and characterisation of SpA features are challenging as the SpA features themselves are highly variable from patient to patient and there is heterogeneity in the methodologies used to define these features.

- Future studies should focus on standardising the variables collected in IBD-SpA cohorts and defining SpA phenotypes in IBD-SpA in order to better characterise this disease entity and advance the field.

prevalence of SpA in patients with IBD varies but is estimated to be as high as $46 \% .^{1}$ Clinical evaluation of patients as well as research studies in IBD cohorts tend to be complex because they require, ideally, coordination between two different subspecialties. Most gastroenterologists are not sufficiently experienced to identify and differentiate inflammatory from degenerative musculoskeletal (MSK) disease or fibromyalgia. Conversely, rheumatologists are generally not secure in their ability to diagnose and distinguish IBD from other gastrointestinal manifestations such as irritable bowel syndrome or coeliac disease. Furthermore, the assessment and management of patients with SpA in IBD is hampered by an incomplete understanding of the pathogenesis, presentation and natural history of the SpA associated with IBD.

Data from several IBD-SpA cohorts have been published. Although a meta-analysis 
assessing the incidence and prevalence of SpA in IBD has been previously reported, ${ }^{2}$ we feel that a critical review of cohort design with particular attention to the process of collection of data regarding specific SpA phenotypes further adds to the literature as a significant gap in knowledge is how SpA subsets are defined in the setting of IBD.

In this paper, we review published data on existing IBD-SpA cohorts with a specific emphasis on study design from the rheumatologic perspective. This manuscript addresses the problems of consistency and fidelity in the description of SpA phenotypes in IBD studies. We hope that employing the findings of this review will permit future IBD-SpA cohorts to be more uniformly developed and will provide more consistent data for research and clinical care purposes.

\section{METHODS}

\section{Literature search}

A systematic literature review was performed using established best practices. ${ }^{3}$ Databases PubMed, Ovid, Scopus, Cinahl, Medline, Web of Science and Cochrane were searched using four complementary search strategies (online supplemental table 1). The following terms were used: IBD, CD, UC, SpA, spondylitis, spondyloarthropathy, arthritis, ankylosing spondylitis (AS), enteropathic arthritis, sacroiliitis, MSK, articular, back pain, EIM. The literature search was performed in March of 2020 and dates for study inclusion were January 2000 to March 2020. Articles selected for inclusion were limited to full text, English language articles. Reviews, meta-analyses, case reports and paediatric studies were excluded. The reference lists of included studies were examined for additional studies eligible for inclusion.
Article titles were first reviewed for inclusion by one study investigator (MS). Abstracts and the full text were further screened by MS for final inclusion and confirmed by the co-authors (MHW, JE, KAK, SS). Studies were included if they evaluated the prevalence/incidence of SpA in a cohort of patients with IBD.

\section{Data extraction}

Data were extracted by one investigator (MS) and reviewed by the co-authors. A prespecified data extraction form was jointly developed (online supplemental table 2). The following data were collected: study setting and design, duration of follow-up, number of patients with IBD, type of IBD, use of SpA classification criteria, SpA phenotypes, method of rheumatologic evaluation, imaging modalities used (including imaging of symptomatic and/or asymptomatic participants) and rheumatologist involvement. Rheumatologist involvement was defined as mention of rheumatologist participation in the study or inclusion of at least one study author with a rheumatology affiliation. The prevalence and/or incidence of axial and peripheral SpA in the composite IBD group, individualised for $\mathrm{CD}$ and $\mathrm{UC}$ where available, was also collected.

We recorded how studies reported SpA. AS was defined by investigator opinion or by the modified New York criteria $(\mathrm{mNY})$. Axial SpA (axSpA) was defined by investigator opinion, imaging evidence for axial inflammation or published classification criteria: Assessment of Spondyloarthritis International Society (ASAS), ${ }^{45}$ European Spondyloarthropathy Study Group (ESSG), ${ }^{6}$ Amor ${ }^{7}$ or other. ${ }^{89}$ Peripheral SpA (pSpA) was defined by investigator opinion or accepted classification criteria for $\mathrm{pSpA}$ (as above). If studies did not distinguish

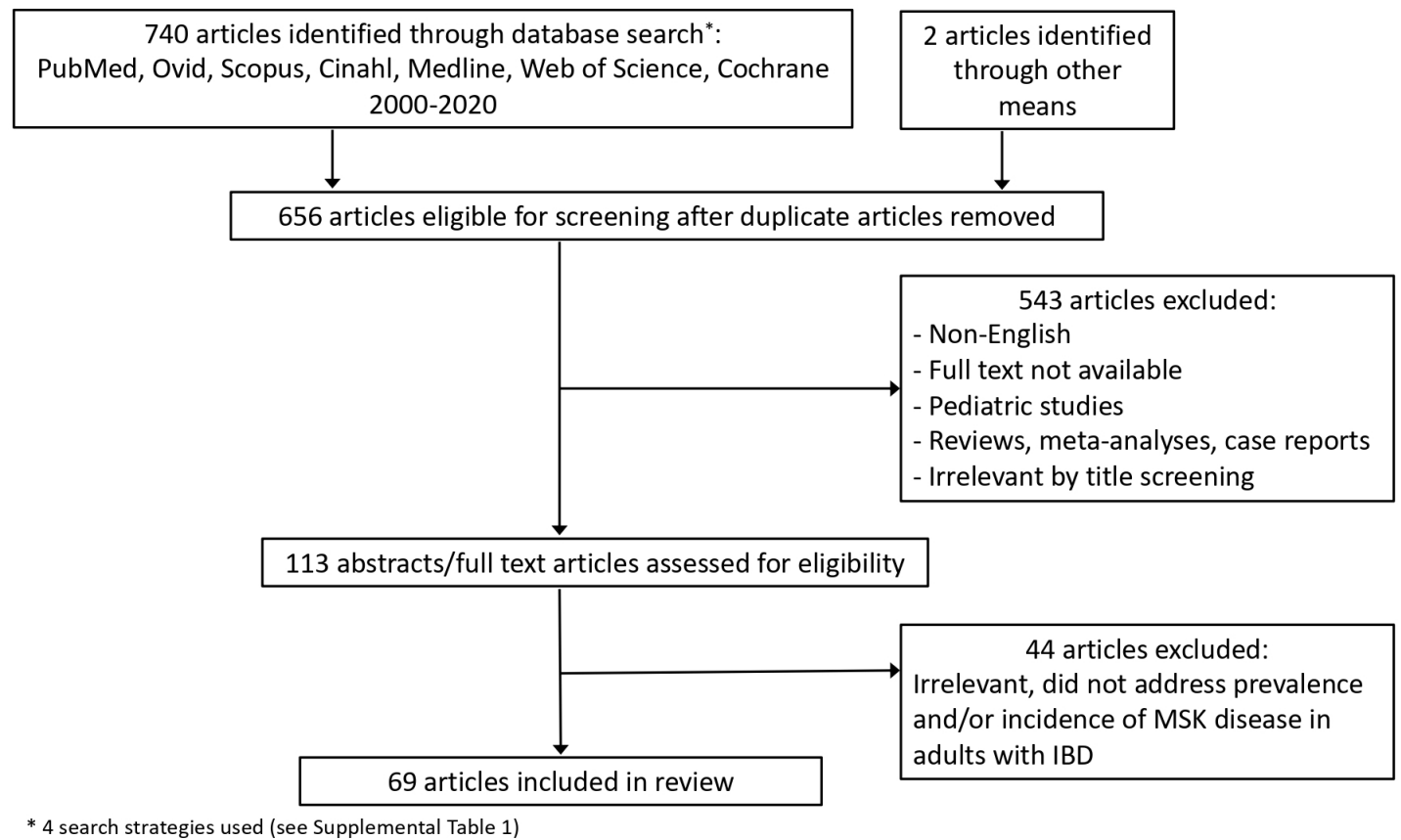

Figure 1 Article Selection. IBD, inflammatory bowel disease; MSK, musculoskeletal. 
between axSpA and $\mathrm{pSpA}$, we considered them as reporting SpA not otherwise specified (SpA NOS). Studies were further categorised and analysed based on whether the patients with IBD were prospectively enrolled or retrospectively analysed. Studies were categorised based on whether the patients with IBD were prospectively enrolled into a cohort from gastroenterology (GI) departments at the time the study was initiated and subsequently assessed either cross-sectionally or longitudinally. This is in contrast to retrospective chart review or claims database studies that did not enrol new patients into their study. We assumed that prospectively enrolled cohorts provide the optimal way to create future IBD-SpA cohorts because they define important variables in advance and collect the data in a consistent manner. Hence, we focused our analysis on prospectively enrolled cohorts only.

\section{Patient and public involvement}

There was no patient or public involvement in this research study.

\section{Statistical analysis}

Descriptive statistics (means or medians when the data were not normally distributed) were calculated using Microsoft Excel.

\section{RESULTS}

\section{Literature review}

We performed a systemic literature review of studies that evaluated axial and peripheral SpA phenotypes in IBD cohorts focusing on aspects of study design (figure 1). The initial database search yielded 740 articles; two additional articles were identified through bibliography review. Eighty-six articles were duplicates and removed, leaving 656 articles for screening. After removing nonEnglish language articles, reviews, meta-analyses, paediatric studies and case reports, 113 studies remained for abstract/full text assessment. Of these, 44 studies were excluded because they did not address prevalence and/ or incidence of SpA in IBD, resulting in 69 articles for critical review.

\section{Study design characteristics}

Major characteristics of the 69 individual studies are shown in online supplemental tables 3,4). Focusing on study design, 54/69 (78\%) were clinic-based and 15/69 $(22 \%)$ were population-based. Forty-seven $(68 \%)$ were single-centre and 22/69 (32\%) were multicentre. Sixty studies $(87 \%)$ were cross-sectional and 9/69 $(13 \%)$ were longitudinal. The median duration of follow-up in the longitudinal studies was 3.5 years (range $1-25$ years). The median age of patients at the time of the study was 41.9 years (range 32.6-50.6 years) and male patients made up a median of $49.6 \%$ studied patients (range 31.2\%$100 \%)$. Most studies $(36 / 69,52 \%)$ originated in Europe, followed by the Near East $(12 / 69,17 \%)$, North America $(10 / 60,14 \%)$, Asia $(8 / 69,12 \%)$, South America (2/69,
$3 \%)$ and Australia $(1 / 69,1 \%)$. The median number of patients with IBD across all studies was 247 patients (range 44-56 097 patients). Forty-four studies (64\%) reported data separately for $\mathrm{CD}$ and UC, whereas 19 (27\%) analysed either CD or UC. Six studies (9\%) reported data for IBD without distinguishing between $\mathrm{CD}$ and UC. Undifferentiated IBD was reported in 9/69 (13\%). Eight studies $(11 \%)$ assessed for family history of SpA, 42/60 $(61 \%)$ evaluated EIMs, however, only 7 (10\%) evaluated for other comorbidities such as diabetes and hypertension, among others. Forty-five studies $(65 \%)$ used some form of MSK imaging. Inflammatory back pain (IBP) was reported in 25/69 (36\%). The prevalence and/or incidence of AS, axSpA, pSpA and SpA NOS was reported in 43/69 (62\%), 47/69 (68\%), 41/69 (69\%) and 25/69 $(36 \%)$, respectively. The median prevalence of AS/ axSpA in IBD was $5 \%$ (range $1 \%-46 \%$ ) and in pSpA $16 \%$ (range 1\%-43\%). Forty-five studies $(65 \%)$ evaluated SpA phenotypes in prospectively enrolled patients with IBD (table 1): 28/45 (62\%) evaluated both axSpA (including AS) and pSpA, 10/45 (22\%) evaluated axSpA (including AS) only and $7 / 45(16 \%)$ evaluated pSpA only. The following sections will examine these studies in greater detail.

\section{Axial disease in IBD: study characteristics}

In studies that evaluated axial disease (table 2), the presence of IBP was analysed in 20/38 (53\%). Twenty-six $(68 \%)$ used established SpA classification criteria. Modified New York, ASAS, ESSG and Amor criteria were used in $17 / 38(45 \%), 11 / 38(29 \%), 8 / 38(21 \%)$ and $3 / 38$ $(8 \%)$, respectively. Some studies used more than one set of classification criteria. The ASAS classification criteria have been increasingly used since their publication in 2009. ${ }^{45}$ A similar fraction of papers published in 2009 or later did not use any SpA criteria compared with studies published before 2009 (33\% vs 29\%). However, 69\% of the studies published after 2014 incorporated ASAS classification criteria, compared with $0 \%$ of the studies published from 2009 to 2014.

Rheumatologists were involved in 30/38 (79\%) studies. A physical examination was included in 29/38 (76\%), which was performed by a rheumatologist in 18/38 $(47 \%)$. Other methods of clinical evaluation included self-report in $6 / 38(16 \%)$ and medical record review in $6 / 38(16 \%)$.

\section{Axial disease in IBD: imaging}

Imaging was performed in 29/38 (76\%) of all studies evaluating axial disease (table 2). The frequency of imaging modalities used was as follows: X-ray of the pelvis or sacroiliac joints (SIJ) in 18/38 (47\%), X-ray of the spine in $11 / 38$ (29\%), MRI of the pelvis/SIJ $7 / 38$ (18\%), MRI of the spine in 2/39 $(5 \%)$ and CT of the pelvis/SIJ in 4/38 (11\%). Imaging of the intestine such as CT or MR enterography (MRE) were re-analysed for SpA phenotypes in 1/38 (3\%). Seven studies (18\%) did not specify what axial locations had been imaged. MRI of 
Table 1 Study characteristics-prospectively enrolled cohorts

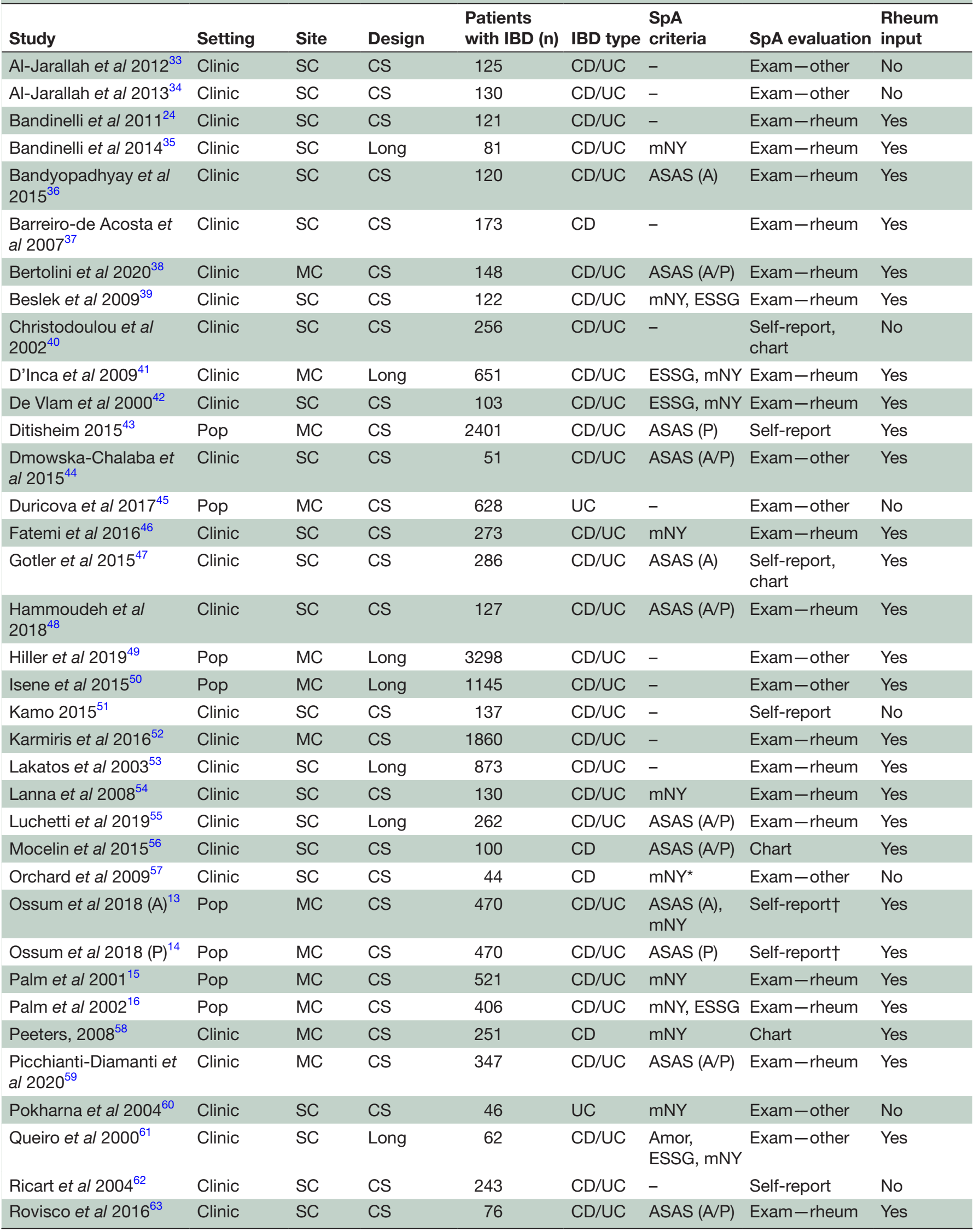


Table 1 Continued

\begin{tabular}{|c|c|c|c|c|c|c|c|c|}
\hline Study & Setting & Site & Design & $\begin{array}{l}\text { Patients } \\
\text { with IBD (n) }\end{array}$ & IBD type & $\begin{array}{l}\text { SpA } \\
\text { criteria }\end{array}$ & SpA evaluation & $\begin{array}{l}\text { Rheum } \\
\text { input }\end{array}$ \\
\hline Sahli et al $2018^{64}$ & Clinic & SC & CS & 64 & CD/UC & $\begin{array}{l}\text { ASAS (A), } \\
\text { Amor }\end{array}$ & Exam-rheum & Yes \\
\hline Salvarani et al $2001^{65}$ & Clinic & $\mathrm{MC}$ & CS & 160 & CD/UC & mNY, ESSG & Exam-rheum & Yes \\
\hline Steer et al $2003^{66}$ & Clinic & SC & CS & 134 & CD & $\mathrm{mNY}$ & Exam-other & Yes \\
\hline Stolwijk et al $2013^{67}$ & Clinic & SC & CS & 350 & CD/UC & - & $\begin{array}{l}\text { Self-report, } \\
\text { chart }\end{array}$ & Yes \\
\hline $\begin{array}{l}\text { Subramaniam et al } \\
2015^{68}\end{array}$ & Clinic & SC & CS & 140 & CD/UC & ASAS (A/P) & $\begin{array}{l}\text { Self-report, } \\
\text { chart }\end{array}$ & Yes \\
\hline Turkcapar et al $2006^{69}$ & Clinic & SC & CS & 162 & CD/UC & mNY, ESSG & Exam-rheum & Yes \\
\hline Van Erp et al $2016^{70}$ & Clinic & SC & Long & 255 & CD/UC & $\begin{array}{l}\text { ASAS (A/P), } \\
\text { Amor, } \\
\text { ESSG, mNY }\end{array}$ & Exam-other & Yes \\
\hline Vavricka et al 2011 & Pop & $\mathrm{MC}$ & CS & 950 & CD/UC & - & $\begin{array}{l}\text { Physician } \\
\text { survey }\end{array}$ & No \\
\hline Yuksel et al $2011^{71}$ & Clinic & SC & CS & 357 & CD/UC & - & Exam-rheum & Yes \\
\hline
\end{tabular}

*Adapted for MRI.

†Used rheumatologist physical examination from 5-year follow-up study.

A, axial; ASAS, Assessment of Spondyloarthritis International Society; CD, Crohn's disease; CS, cross-sectional; ESSG, European

Spondyloarthropathy Study Group; IBD, inflammatory bowel disease; Long, longitudinal; MC, multicentre; mNY, modified New York criteria;

P, peripheral; Pop, population; Rheum, rheumatologist; SC, single centre; SpA, spondyloarthritis; UC, ulcerative colitis.

the pelvis/SIJ was only performed in studies published in 2009 or later. Fourteen studies $(48 \%)$ imaged both symptomatic and asymptomatic patients while $7 / 29(24 \%)$ imaged symptomatic patients only. Eight studies (28\%) did not specify whether imaging was done in symptomatic or asymptomatic patients.

\section{Peripheral joint disease in IBD: study characteristics}

Thirty-five of 69 studies (51\%) evaluated peripheral joint disease (table 3). SpA criteria (ASAS, ESSG, Amor) were employed to define peripheral disease in 16/35 (46\%). Three studies specifically excluded patients with osteoarthritis (OA) or fibromyalgia and six studies recorded the presence $\mathrm{OA}$ and/or fibromyalgia. The majority of studies, 26/35 (74\%), did not mention whether OA and fibromyalgia were assessed.

Direct rheumatologist involvement was recorded in 28/35 (80\%) studies. A physical examination performed by any provider was done in 26/35 (74\%) and physical examination by a rheumatologist was performed in $19 / 35(54 \%)$. Self-report was used in $7 / 35(20 \%)$ and medical record review was used in 12/35 (34\%).

\section{Peripheral joint disease in IBD: imaging}

Peripheral joint imaging was performed in 14/35 (40\%) studies evaluating peripheral disease in IBD cohorts. X-ray of peripheral joints was done in $8 / 35$ (23\%), ultrasound in 5/35 (14\%) and whole-body scintigraphy in $1 / 35(3 \%)$. Four of the studies that incorporated ultrasound used formal/validated ultrasound outcome measures. $^{1011}$ Three of the five ultrasound studies explicitly imaged asymptomatic patients. Peripheral imaging was used in less than half of the studies, and despite the general widespread and increasing use in rheumatology, ultrasound was infrequently used.

\section{Peripheral joint disease in IBD: sub-phenotype evaluation}

Twenty-seven (77\%) of the studies that evaluated peripheral disease in IBD cohorts characterised peripheral $\mathrm{SpA}$ in more detail. Enthesitis was analysed in 18/27 (67\%), monoarthritis or oligoarthritis in 13/27 (48\%), dactylitis in 13/27 (48\%), arthralgia in 12/27 (44\%) and polyarthritis in 10/26 (39\%). Two studies analysed all of these five sub-phenotypes, three studies analysed four phenotypes, seven studies analysed three phenotypes, nine studies analysed two phenotypes, four studies analysed one phenotype and two studies only reported other phenotypes such as fibromyalgia, OA or bursitis. Data for type 1 and type 2 arthritis were reported in six studies; type 1 and type 2 arthritis is a categorisation of IBD-associated arthritis described and used exclusively in the GI literature. ${ }^{12}$ Type 1 arthritis describes an acute and self-limiting oligoarthritis that parallels IBD activity while type 2 arthritis describes a chronic, symmetric polyarthritis that does not parallel IBD activity.

A physical examination by a rheumatologist was performed in 19/35 (54\%) of the studies that assessed peripheral joint disease. Of these studies, $95 \%$ distinguished patients by different characteristics of peripheral SpA manifestations (monoarthritis or oligoarthritis, polyarthritis, enthesitis, dactylitis, arthralgia). Fifty-three per cent $(10 / 19)$ used pSpA classification criteria, and $10 / 19(53 \%)$ had peripheral imaging performed. In 
Table 2 Study characteristics - studies evaluating axial joint disease

\begin{tabular}{|c|c|c|c|c|c|c|c|}
\hline Study & $\begin{array}{l}\text { SpA } \\
\text { criteria }\end{array}$ & $\begin{array}{l}\text { Physical } \\
\text { exam }\end{array}$ & $\begin{array}{l}\text { Exam } \\
\text { provider }\end{array}$ & $\begin{array}{l}\text { Other } \\
\text { evaluation }\end{array}$ & $\begin{array}{l}\text { Axial } \\
\text { phenotype }\end{array}$ & Axial imaging & $\begin{array}{l}\text { Subjects } \\
\text { imaged }\end{array}$ \\
\hline Al-Jarallah et al $2012^{33}$ & - & Yes & Other & - & $\mathrm{AxSpA}$ & $\begin{array}{l}\text { MRI spine } \\
\text { MRI pelvis/SIJ } \\
\text { X-ray** }\end{array}$ & Sx/aSx \\
\hline Al-Jarallah et al $2013^{34}$ & - & Yes & Other & - & AS, axSpA & - & - \\
\hline Bandinelli et al $2014^{35}$ & $\mathrm{mNY}$ & Yes & Rheum & - & AxSpA & $\begin{array}{l}\text { X-ray pelvis/SIJ } \\
\text { MRI pelvis/SIJ }\end{array}$ & Sx/aSx \\
\hline $\begin{array}{l}\text { Bandyopadhyay et al } \\
2015^{36}\end{array}$ & ASAS & Yes & Rheum & - & AS, axSpA & $\begin{array}{l}\text { X-ray pelvis/SIJ } \\
\text { X-ray spine } \\
\text { MRI pelvis/SIJ } \\
\text { MRI spine }\end{array}$ & Sx/aSx \\
\hline $\begin{array}{l}\text { Barreiro-de Acosta et al } \\
2007^{37}\end{array}$ & - & Yes & Rheum & - & AS, axSpA & X-ray* & Sx \\
\hline Bertolini et al $2020^{38}$ & ASAS & Yes & Rheum & - & AxSpA & MRI pelvis/SIJ & Sx/aSx \\
\hline Beslek et al $2009^{39}$ & $\begin{array}{l}\mathrm{mNY} \\
\mathrm{ESSG}\end{array}$ & Yes & Rheum & - & AS & $\begin{array}{l}\text { X-ray pelvis/SIJ } \\
\text { MRI pelvis/SIJ }\end{array}$ & Sx \\
\hline $\begin{array}{l}\text { Christodoulou et al } \\
2002^{40}\end{array}$ & - & No & - & $\begin{array}{l}\text { Self-report, } \\
\text { chart }\end{array}$ & AxSpA & - & - \\
\hline D'Inca et al $2009^{41}$ & $\begin{array}{l}\text { ESSG, } \\
\text { mNY }\end{array}$ & Yes & Rheum & - & AS, axSpA & $\begin{array}{l}\text { X-ray spine } \\
\text { MRI spine } \\
\text { X-ray hip } \\
\text { MRI hip bone } \\
\text { scintigraphy }\end{array}$ & Sx \\
\hline De Vlam et al $2000^{42}$ & $\begin{array}{l}\text { ESSG, } \\
\mathrm{mNY}\end{array}$ & Yes & Rheum & - & AS, axSpA & X-ray pelvis/SIJ & Sx/aSx \\
\hline $\begin{array}{l}\text { Dmowska-Chalaba et } \\
\text { al } 2015^{44}\end{array}$ & ASAS & Yes & Other & - & $\mathrm{AxSpA}$ & $\mathrm{X}$-ray and $\mathrm{MRI}^{*}$ & - \\
\hline Duricova et al $2017^{45}$ & - & Yes & Other & - & AxSpA & - & - \\
\hline Fatemi et al $2016^{46}$ & $\mathrm{mNY}$ & Yes & Rheum & - & AS & X-ray pelvis/SIJ & Sx \\
\hline Gotler et al $2015^{47}$ & ASAS & No & - & $\begin{array}{l}\text { Self-report, } \\
\text { chart }\end{array}$ & AxSpA & $\begin{array}{l}\text { CT pelvis/SIJ } \\
\text { Gl studies } \\
\text { analysed } \\
\text { for axial } \\
\text { phenotypes }\end{array}$ & Sx/aSx \\
\hline $\begin{array}{l}\text { Hammoudeh et al } \\
2018^{48}\end{array}$ & ASAS & Yes & Rheum & - & AS, axSpA & $\begin{array}{l}\text { X-ray pelvis/SIJ } \\
\text { X-ray spine }\end{array}$ & - \\
\hline Hiller et al $2019^{49}$ & - & Yes & Other & - & AS & - & - \\
\hline Isene et al $2015^{50}$ & - & Yes & Other & - & AS, axSpA & - & - \\
\hline Karmiris et al $2016^{52}$ & - & Yes & Rheum & - & AS, axSpA & $\mathrm{X}$-ray and $\mathrm{MRI}^{\star}$ & - \\
\hline Lakatos et al $2003^{53}$ & - & Yes & Rheum & - & $\mathrm{AxSpA}$ & $\mathrm{X}$-ray and $\mathrm{MRI}{ }^{*}$ & - \\
\hline Lanna et al $2008^{54}$ & $\mathrm{mNY}$ & Yes & Rheum & - & AS, axSpA & $\begin{array}{l}\text { X-ray pelvis/SIJ } \\
\text { X-ray spine }\end{array}$ & Sx/aSx \\
\hline Luchetti et al $2019^{55}$ & ASAS & Yes & Rheum & - & AS, axSpA & $\mathrm{X}$-ray and $\mathrm{MRI}^{*}$ & Sx \\
\hline Mocelin et al $2015^{56}$ & ASAS & No & - & Chart & AS, axSpA & - & - \\
\hline Orchard et al $2009^{57}$ & $\mathrm{mNY} \dagger$ & Yes & Other & - & AS, axSpA & MRI pelvis/SIJ & Sx/aSx \\
\hline $\begin{array}{l}\text { Ossum et al } 2018 \\
\text { Axial }^{13}\end{array}$ & $\begin{array}{l}\text { ASAS, } \\
\text { mNY }\end{array}$ & No & - & Self-report & AS, axSpA & $\begin{array}{l}\text { X-ray pelvis/SIJ } \\
\text { X-ray spine }\end{array}$ & - \\
\hline Palm et al $2001^{15}$ & $\mathrm{mNY}$ & Yes & Rheum & - & AS & - & - \\
\hline Palm et al $2002^{16}$ & $\begin{array}{l}\mathrm{mNY} \\
\mathrm{ESSG}\end{array}$ & Yes & Rheum & - & AS & $\begin{array}{l}\text { X-ray pelvis/SIJ } \\
\text { X-ray spine }\end{array}$ & - \\
\hline Peeters et al $2008^{58}$ & $\mathrm{mNY}$ & No & - & Chart & AS, axSpA & X-ray pelvis/SIJ & Sx/aSx \\
\hline
\end{tabular}


Table 2 Continued

\begin{tabular}{|c|c|c|c|c|c|c|c|}
\hline Study & $\begin{array}{l}\text { SpA } \\
\text { criteria }\end{array}$ & $\begin{array}{l}\text { Physical } \\
\text { exam }\end{array}$ & $\begin{array}{l}\text { Exam } \\
\text { provider }\end{array}$ & $\begin{array}{l}\text { Other } \\
\text { evaluation }\end{array}$ & $\begin{array}{l}\text { Axial } \\
\text { phenotype }\end{array}$ & Axial imaging & $\begin{array}{l}\text { Subjects } \\
\text { imaged }\end{array}$ \\
\hline Pokharna et al $2004^{60}$ & $\mathrm{mNY}$ & Yes & Other & - & AxSpA & $\begin{array}{l}\text { X-ray pelvis/SIJ } \\
\text { X-ray spine }\end{array}$ & Sx/aSx \\
\hline Queiro et al $2000^{61}$ & $\begin{array}{l}\text { Amor, } \\
\text { ESSG, } \\
\text { mNY }\end{array}$ & Yes & Other & - & AS, axSpA & $\begin{array}{l}\text { X-ray pelvis/SIJ } \\
\text { X-ray spine }\end{array}$ & Sx/aSx \\
\hline Ricart et al $2004^{62}$ & - & No & - & Self-report & AS & - & - \\
\hline Sahli et al $2018^{64}$ & $\begin{array}{l}\text { ASAS, } \\
\text { Amor }\end{array}$ & Yes & Rheum & - & AS, axSpA & $\begin{array}{l}\text { X-ray pelvis/SIJ } \\
\text { X-ray spine } \\
\text { MRI pelvis/SIJ } \\
\text { CT pelvis/SIJ }\end{array}$ & Sx/aSx \\
\hline Salvarani et al $2001^{65}$ & $\begin{array}{l}\text { mNY, } \\
\text { ESSG }\end{array}$ & Yes & Rheum & - & AS, axSpA & X-ray pelvis/SIJ & - \\
\hline Steer et al $2003^{66}$ & $\mathrm{mNY}$ & Yes & Other & - & A AS, axSpA & $\begin{array}{l}\text { X-ray pelvis/SIJ } \\
\text { CT pelvis/SIJ }\end{array}$ & Sx \\
\hline Stolwijk et al $2013^{67}$ & - & No & - & $\begin{array}{l}\text { Self-report, } \\
\text { chart }\end{array}$ & AxSpA & - & - \\
\hline $\begin{array}{l}\text { Subramaniam et al } \\
2015^{68}\end{array}$ & ASAS & No & - & $\begin{array}{l}\text { Self-report, } \\
\text { chart }\end{array}$ & AS, axSpA & X-ray pelvis/SIJ & Sx/aSx \\
\hline Turkcapar et al $2006^{69}$ & $\begin{array}{l}\mathrm{mNY} \\
\mathrm{ESSG}\end{array}$ & Yes & Rheum & - & AS, axSpA & $\begin{array}{l}\text { X-ray pelvis/SIJ } \\
\text { X-ray spine } \\
\text { CT pelvis/SIJ }\end{array}$ & Sx/aSx \\
\hline Van Erp et al $2016^{70}$ & $\begin{array}{l}\text { ASAS, } \\
\text { Amor, } \\
\text { ESSG, } \\
\text { mNY }\end{array}$ & Yes & Other & - & AS, axSpA & $\begin{array}{l}\text { X-ray pelvis/SIJ } \\
\text { X-ray spine }\end{array}$ & Sx \\
\hline Vavricka et al 2011 & - & No & - & $\begin{array}{l}\text { Physician } \\
\text { survey }\end{array}$ & AS & X-ray* & - \\
\hline
\end{tabular}

${ }^{*}$ Axial location not specified.

†Adapted for MRI.

AS, ankylosing spondylitis; ASAS, Assessment of Spondyloarthritis International Society; aSx, asymptomatic; AxSpA, axial spondyloarthritis; CT, CAT Scan; ESSG, European Spondyloarthropathy Study Group; Gl, gastrointestinal; mNY, modified New York critiera; Rheum, rheumatologist; SIJ, sacroiliac joint; SpA, spondyloarthritis; Sx, symptomatic.

7/35 (20\%), a physical examination was performed by a non-rheumatologist provider. Of these studies, only $4 / 7$ (57\%) distinguished patients by arthritis sub-phenotype. Twenty-nine per cent $(2 / 7)$ used pSpA classification criteria, and $3 / 7$ (43\%) used peripheral imaging. In the remaining nine studies $(26 \%)$, no physical examination was performed. Of these studies without a physical examination, $5 / 9$ (56\%) distinguished patients by arthritis subphenotype, 4/9 (44\%) used pSpA classification criteria, $1 / 9(11 \%)$ used peripheral imaging.

\section{DISCUSSION}

In this systematic review of 69 studies that analysed SpA manifestations in IBD cohorts, we found that most were clinic-based $(78 \%)$, single-centre $(68 \%)$ and crosssectional $(87 \%)$ in design. The median number of patients with IBD was 247 (range 44-56 097 patients) and the median prevalence of axSpA and $\mathrm{pSpA}$ in IBD was $5 \%$ (range $1 \%-46 \%$ ) and $16 \%$ (range $1 \%-43 \%$ ), respectively. Thirty-eight studies evaluated axial disease in prospectively enrolled patients with IBD. Of these 38 studies, the presence of IBP was analysed in 53\%, SpA classification criteria were used in $68 \%$ and imaging was performed in $76 \%$. Peripheral $\mathrm{SpA}$ was evaluated in prospectively enrolled patients in 35 studies. Of these 35 studies, SpA classification criteria were used in $46 \%$ and imaging was done $40 \%$. A physical examination was performed in $74 \%$, and in $54 \%$ of these studies, it was done by a rheumatologist. Sub-phenotypes of pSpA (monoarthritis or oligoarthritis, polyarthritis, enthesitis, dactylitis) or arthralgia were variably reported, and $74 \%$ of the studies did not mention whether OA and fibromyalgia had been assessed or excluded.

IBD-SpA is a heterogenous, multifaceted disease. Of the 69 studies included in this review, most were single centre, and the median number of patients enrolled was only 247 . This number is unlikely to be sufficient to describe the full spectrum of IBD-SpA, and larger, multicentre cohorts are needed to better define IBD-SpA. The majority of studies were clinic-based, most commonly 


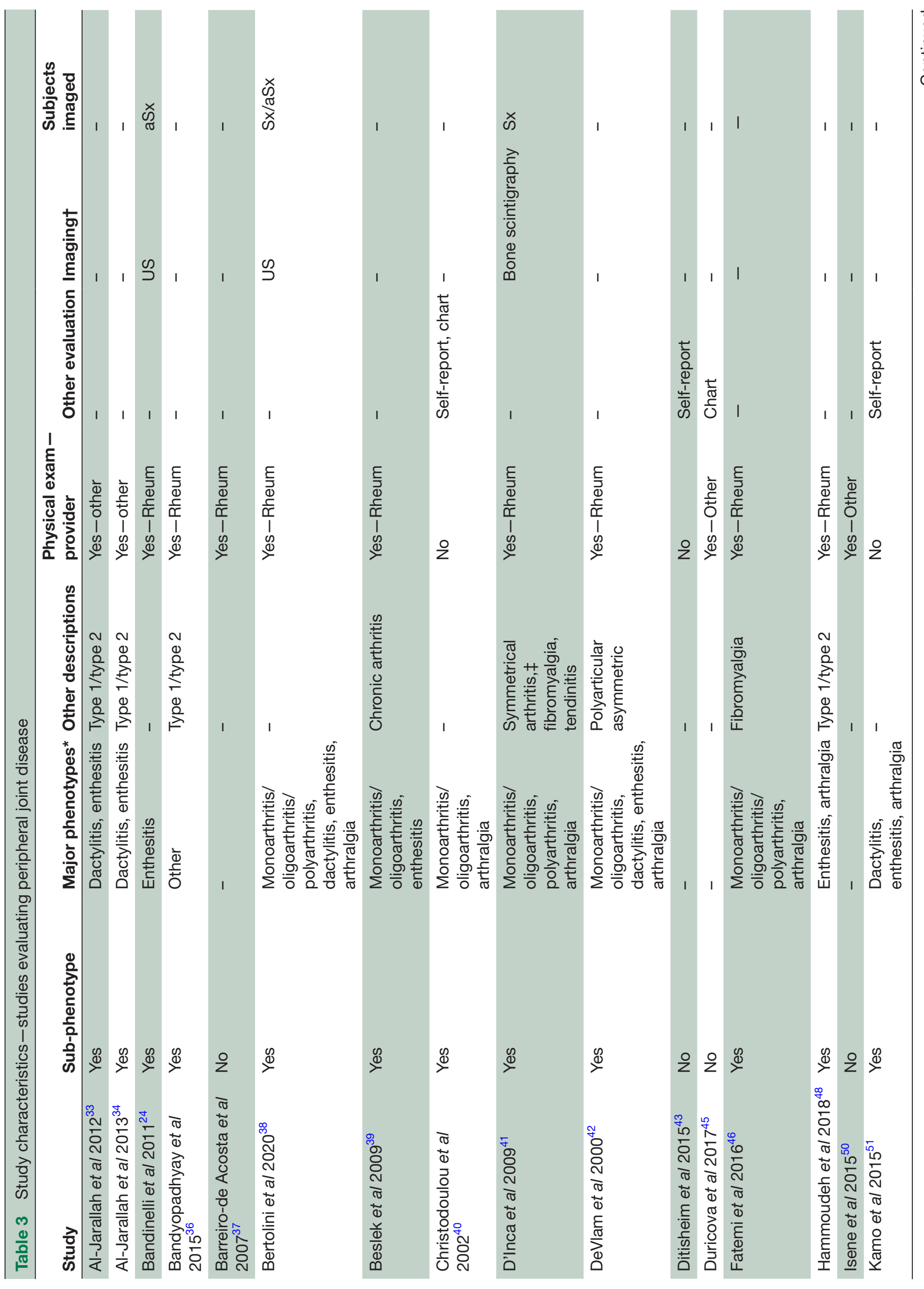




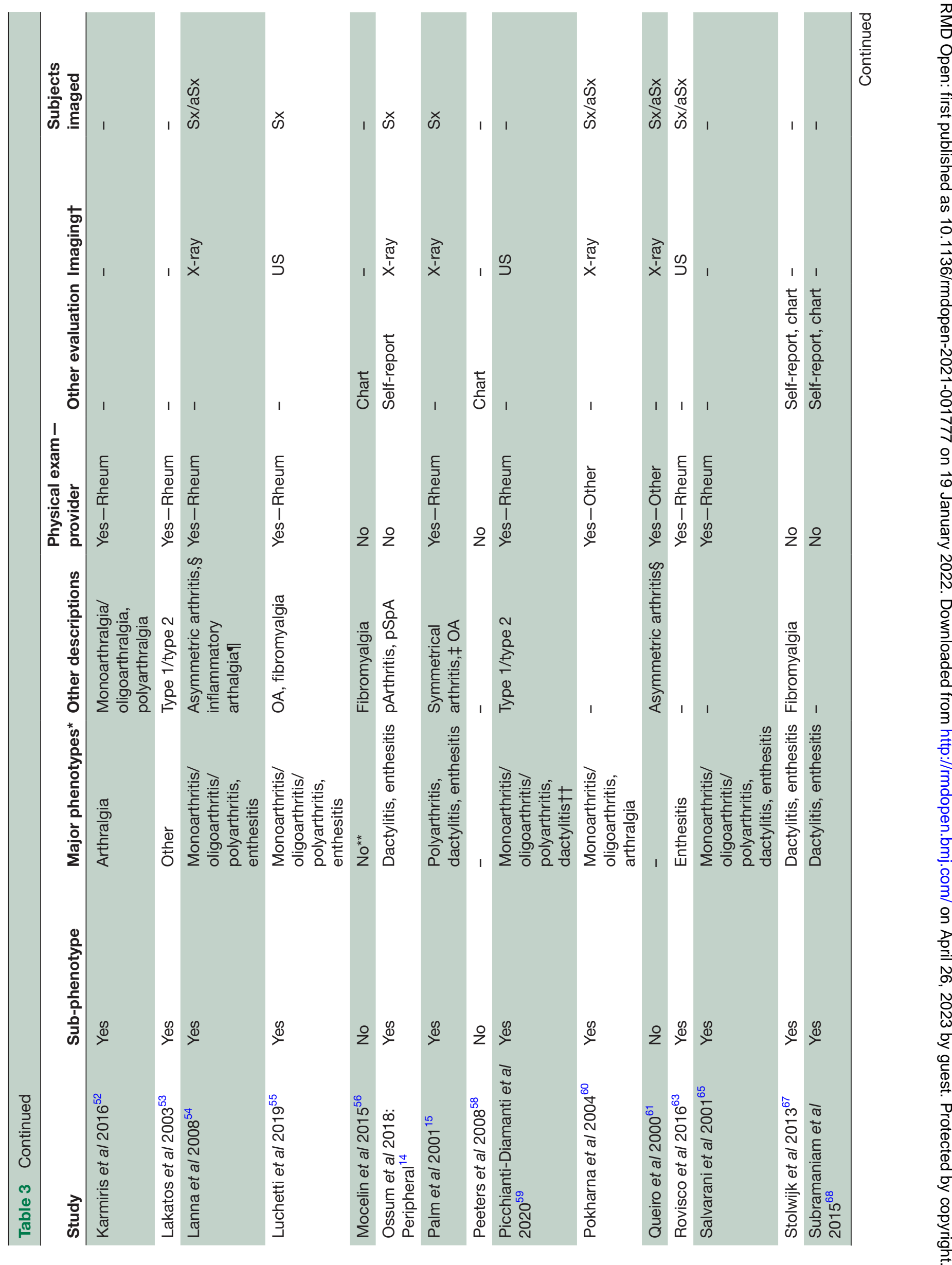




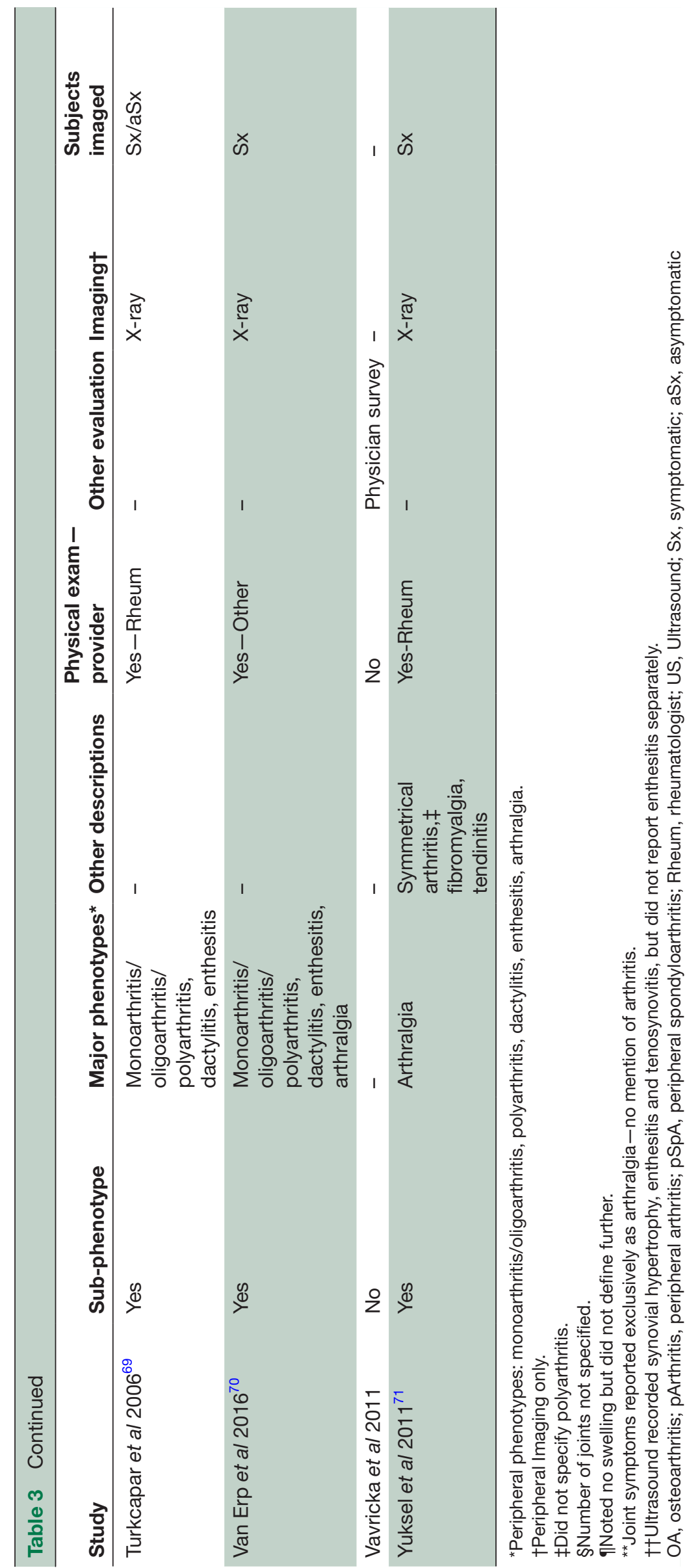


at tertiary care centres, which may not capture a group of patients representative of the entire population of IBD-SpA. The majority of studies were cross-sectional, a design that does not permit an evaluation of the natural history of disease or the detection of incident SpA in IBD. In the Inflammatory Bowel South-Eastern Norway studies, which evaluated SpA in patients with IBD over a 20-year period, ${ }^{13-16}$ the prevalence of $\mathrm{pSpA}$ increased from $11.9 \%$ at 5 years to $26.1 \%$ at 20 years, and the prevalence of AS increased from $3.7 \%$ at 5 years to $4.5 \%$ at 20 years, illustrating that longitudinal studies capture additional patients that are missed in cross-sectional studies.

Across all 69 studies, we found that the composite median prevalence of axSpA and $\mathrm{pSpA}$ in IBD was $5 \%$ (range $1 \%-46 \%$ ) and $16 \%$ (range $1 \%-43 \%$ ), respectively; similar to what has been reported previously in a meta-analysis. ${ }^{2}$ However, the range of IBD-SpA prevalence values across the studies was wide. This may be a result of the variable definition of IBD-SpA across the studies, which ranged from clinical, physician diagnosis to multiple different SpA classification criteria. The characterisation of axial disease in IBD-SpA cohorts varied despite established classification and imaging criteria. ${ }^{4}$ Inflammatory back pain, an important screening tool for axSpA, was only evaluated in $53 \%$ of the 38 studies that assessed axial disease prospectively. Most of the 35 studies that assessed peripheral disease prospectively did not address whether other MSK conditions, such as OA and fibromyalgia, were excluded, which likely confounds the reports of SpA prevalence. Many studies were retrospective and/or claims database studies which may bias findings based on how patients are identified and how patient data are recorded. The range of prevalence of SpA in IBD is wide, and more uniform definitions of SpA in IBD are necessary to better understand the true frequency of SpA in IBD.

Despite accepted imaging criteria used in the evaluation of axSpA ${ }^{4}$ and the prominent role of MRI in the diagnosis and classification of axSpA, ${ }^{4}$ imaging was not always employed in the 38 studies that assessed axial disease prospectively. MRE, a technique that images the bowel, is an important tool used in the evaluation of IBD, and often serendipitously captures information about the SI joints. Though MRE is suboptimal for assessment of the SIJ, the utility of using MRE as a screening tool has been demonstrated, ${ }^{17}$ however, the routine utility of this modality remains unclear. Furthermore, it is unknown whether axSpA in IBD is different from axSpA in patients without IBD. Studies in psoriatic arthritis (PsA) have indicated that axial PsA is distinct from AS/axSpA. ${ }^{18}{ }^{19}$ Early radiographic studies ${ }^{20}$ suggest that axial disease in AS and IBD are morphologically similar, though further research is needed to better define this clinical phenotype.

Ultrasound is increasingly being used in the identification of inflammatory arthritis. ${ }^{21}$ However, very few studies (14\%) used ultrasound to assess peripheral SpA in the 35 studies that addressed peripheral SpA in prospectively enrolled patients with IBD. Ultrasound can objectively identify tenosynovitis or enthesitis, which can aid in early diagnosis and has been shown to predict the transition from psoriasis to PsA. ${ }^{22}{ }^{23}$ Similarly, studies included in this review demonstrated evidence of enthesial disease and erosions in asymptomatic patients with IBD, ${ }^{24}$ identifying subclinical SpA. Ultrasound has the potential provide a unique opportunity to assess $\mathrm{SpA}$, in particular early disease, in IBD.

While it is well-documented that $\mathrm{SpA}$ is the most common EIM in IBD, relatively little is known about clinical sub-phenotypes. Only a small fraction of the 35 studies that assessed peripheral disease prospectively analysed the whole SpA spectrum of IBD-SpA that includes axial disease, monoarthritis or oligoarthritis, polyarthritis, dactylitis and enthesitis. This assessment may have important therapeutic implications. For example, in patients with predominant enthesitis, a biologic may provide efficacy that supersedes conventional synthetic disease modifying anti-rheumatic medications. ${ }^{25-27}$ The categorisation of SpA in IBD as type 1 and 2 arthritis ${ }^{12}$ has not been validated prospectively, though the use of this categorisation persists in the gastrointestinal literature and in clinical care. A granular categorisation of the SpA phenotype, perhaps including type 1 and 2 designations, may provide important insights into pathogenesis. Additionally, some of these studies identified arthralgia, though often did not specify other conditions such as fibromyalgia and $\mathrm{OA}$ which are common conditions in the general population. Fibromyalgia has been demonstrated in up to $30 \%$ of patients with $\mathrm{IBD},{ }^{28}$ however, only about $1 / 3$ of the 35 studies that assessed peripheral disease prospectively made any note of OA or fibromyalgia. From a management perspective, it is critical to identify these entities as therapy for these conditions is vastly different.

Among all prospectively enrolled cohorts evaluated, not all studies used SpA classification criteria, and when employed, there was a range of classification criteria used. We observed a strong recent trend to apply ASAS classification criteria. The ASAS criteria were developed for use in SpA. IBD-SpA may have different clinical characteristics much as axial PsA demonstrates different characteristics when compared with AS. ${ }^{18} 19$ The performance of the ASAS criteria in IBD-SpA has not been studied in sufficient detail to know if they are applicable. For instance, an elevated serum CRP level is listed in the ASAS SpA criteria, however, this can be elevated independently in IBD and may not be reflective of SpA activity. ASAS criteria include HLA-B27 status. While the prevalence of HLA-B27 in AS in $85 \%-90 \%,{ }^{29}$ it is much lower in IBD$\mathrm{SpA}$, reported in up to $60 \% .^{29}$

Our study reported herein has several strengths and limitations. While prior studies have looked at the prevalence/incidence of SpA in IBD, to the best of our knowledge, this is the first study that systematically and comprehensively investigated study design and characteristics of SpA phenotyping in IBD. The systematic literature review was performed using established best 
practices $^{3}$ and differences of study design were identified. Limitations of this study include restricting the review to English language articles. The study focused on adult disease, and future research should include characterising paediatric IBD-SpA. Our study was limited by incomplete or absent reporting of variables such as imaging of asymptomatic patients as well as the presence of OA and fibromyalgia. Additionally, full descriptions of the individual locations that were imaged were not always present. We did not record whether laboratory or pathology data had been collected. Finally, we did not compare how different study settings affect prevalence rates. Studies were identified and data extraction were performed by a single member of the group, rather than done in duplicate, though data were discussed by the entire group.

\section{CONCLUSION}

Although patients with IBD and SpA appear to share many clinical, immunologic and genetic characteristics, ${ }^{30-32}$ the exact relationship between these two entities has never been comprehensively defined. Attempts at identification and characterisation of the SpA features in IBD are beset with two problems; SpA features themselves are highly variable from patient to patient and there is heterogeneity in the methodologies used to define these features. Of importance, it is not clear that standard accepted SpA classification criteria developed independently without consideration of IBD status are entirely applicable to IBD patients with SpA. Developing a standard set of variables to be collected in IBD-SpA cohorts will allow for a better definition of SpA phenotypes in IBD-SpA. A concrete characterisation of these features will facilitate future research endeavours and ultimately improve patient management.

Based on our data, we conclude that a study that attempts to comprehensively describe axial and peripheral SpA phenotypes in IBD requires a large number of patients from a range of settings. Therefore, an ideal study would be multicentre and population-based. However, initiating a clinic-based or region-based study may be a more practical starting point. Patients should be followed longitudinally. Ideally and before any further work is done, validation of prior SpA classification tools (such as the ASAS classification criteria) should take place in patients with IBD. The set of clinical variables collected should include IBP and the exclusion of other inflammatory and non-inflammatory MSK conditions such as $\mathrm{OA}$ and fibromyalgia. A physical examination should always be performed, ideally by a rheumatologist or, alternatively, by a trained healthcare provider, and data on arthritis patterns and presence of enthesitis or dactylitis should be collected. At a minimum, imaging with both plain radiographs and MRI of the SIJs should be performed, and the assessment of peripheral disease should incorporate ultrasound. Finally, research participants should be followed longitudinally with formal semiannual evaluations and intermittent assessments as needed for disease flares. The ideal starting point would be a joint effort by gastroenterologists and rheumatologists to create a joint statement that defines IBD-SpA.

\section{Author affiliations}

${ }^{1}$ Division of Rheumatology, Hospital for Special Surgery, New York, New York, USA ${ }^{2}$ Division of Rheumatology, Inflammation and Immunity, Brigham and Women's Hospital and Harvard Medical School, Boston, Massachusetts, USA

${ }^{3}$ Department of Medicine, Division of Rheumatology, University of ColoradoAnschutz Medical Campus, Aurora, Colorado, USA

${ }^{4}$ Department of Medicine, New York-Presbyterian Hospital/Weill Cornell Medical Center, New York, New York, USA

${ }^{5}$ Department of Rheumatology and Immunology, Stanford University School of Medicine, Palo Alto, California, USA

Acknowledgements We would like to thank the Spondyloarthritis Research and Treatment Network (SPARTAN) for providing a platform for our working group.

Contributors MS performed the literature search and data collection. All authors contributed equally to the study design, data analysis and writing.

Funding The authors have not declared a specific grant for this research from any funding agency in the public, commercial or not-for-profit sectors.

Competing interests None declared.

Patient consent for publication Not applicable.

Provenance and peer review Not commissioned; externally peer reviewed.

Open access This is an open access article distributed in accordance with the Creative Commons Attribution Non Commercial (CC BY-NC 4.0) license, which permits others to distribute, remix, adapt, build upon this work non-commercially, and license their derivative works on different terms, provided the original work is properly cited, appropriate credit is given, any changes made indicated, and the use is non-commercial. See: http://creativecommons.org/licenses/by-nc/4.0/.

ORCID iD

Monica Schwartzman http://orcid.org/0000-0002-2284-2829

\section{REFERENCES}

1 Olivieri I, Cantini F, Castiglione F, et al. Italian expert panel on the management of patients with coexisting spondyloarthritis and inflammatory bowel disease. Autoimmun Rev 2014;13:822-30.

2 Karreman MC, Luime JJ, Hazes JMW, et al. The prevalence and incidence of axial and peripheral spondyloarthritis in inflammatory bowel disease: a systematic review and meta-analysis. J Crohns Colitis 2017;11:631-42.

3 Moher D, Liberati A, Tetzlaff J, et al. Preferred reporting items for systematic reviews and meta-analyses: the PRISMA statement. BMJ 2009;339:b2535.

4 Rudwaleit M, van der Heijde D, Landewé R, et al. The development of assessment of spondyloarthritis International Society classification criteria for axial spondyloarthritis (Part II): validation and final selection. Ann Rheum Dis 2009;68:777-83.

5 Rudwaleit M, van der Heijde D, Landewé R, et al. The assessment of spondyloarthritis International Society classification criteria for peripheral spondyloarthritis and for spondyloarthritis in general. Ann Rheum Dis 2011;70:25-31.

6 Dougados M, van der Linden S, Juhlin R, et al. The European Spondylarthropathy Study Group preliminary criteria for the classification of spondylarthropathy. Arthritis Rheum 1991;34:1218-27.

7 Amor B, Dougados M, Mijiyawa M. [Criteria of the classification of spondylarthropathies]. Rev Rhum Mal Osteoartic 1990;57:85-9.

8 Dale K, Vinje O. Radiography of the spine and sacro-iliac joints in ankylosing spondylitis and psoriasis. Acta Radiol Diagn 1985;26:145-59.

9 Chan JSI, Salonen D, et al. SAT0271 development of a novel Si joint CT score for diagnosis of axial spondylitis.: Annals of rheumatic disease, 2015: 756-7.

10 Balint PV, Kane D, Wilson $\mathrm{H}$, et al. Ultrasonography of entheseal insertions in the lower limb in spondyloarthropathy. Ann Rheum Dis 2002;61:905-10.

11 Bruyn GA, lagnocco A, Naredo E, et al. OMERACT definitions for ultrasonographic pathologies and elementary lesions of rheumatic disorders 15 years on. J Rheumatol 2019;46:1388-93. 
12 Orchard TR, Wordsworth BP, Jewell DP. Peripheral arthropathies in inflammatory bowel disease: their articular distribution and natural history. Gut 1998;42:387-91.

13 Ossum AM, Palm Øyvind, Lunder AK, et al. Ankylosing spondylitis and axial spondyloarthritis in patients with long-term inflammatory bowel disease: results from 20 years of follow-up in the IBSEN study. J Crohns Colitis 2018;12:96-104.

14 Ossum AM, Palm Øyvind, Cvancarova M, et al. Peripheral arthritis in patients with long-term inflammatory bowel disease. Results from 20 years of follow-up in the IBSEN study. Scand J Gastroenterol 2018;53:1250-6.

15 Palm $\varnothing$, Moum B, Jahnsen J, et al. The prevalence and incidence of peripheral arthritis in patients with inflammatory bowel disease, a prospective population-based study (the IBSEN study). Rheumatology 2001;40:1256-61.

16 Palm O, Moum B, Ongre A, et al. Prevalence of ankylosing spondylitis and other spondyloarthropathies among patients with inflammatory bowel disease: a population study (the IBSEN study). Rheumatol 2002;29:511-5.

17 Malik F, Levine I, Castillo G. Magnetic Resonance Enterography as a Screening Tool to Detect Sacroiliitis in Crohn's Disease: Association with Clinical and Endoscopic Markers of Crohn's Disease Activity [abstract]. Arthritis Rheumatol 2019.

18 Feld J, Chandran V, Haroon N, et al. Axial disease in psoriatic arthritis and ankylosing spondylitis: a critical comparison. Nat Rev Rheumatol 2018;14:363-71.

19 Feld J, Ye JY, Chandran V, et al. Is axial psoriatic arthritis distinct from ankylosing spondylitis with and without concomitant psoriasis? Rheumatology 2020;59:1340-6.

20 McEwen C, DiTata D, Lingg C, et al. Ankylosing spondylitis and spondylitis accompanying ulcerative colitis, regional enteritis, psoriasis and Reiter's disease. A comparative study. Arthritis Rheum 1971;14:291-318.

21 Kaeley GS, Bakewell C, Deodhar A. The importance of ultrasound in identifying and differentiating patients with early inflammatory arthritis: a narrative review. Arthritis Res Ther 2020;22:1.

22 Freeston JE, Coates LC, Nam JL, et al. Is there subclinical synovitis in early psoriatic arthritis? a clinical comparison with gray-scale and power Doppler ultrasound. Arthritis Care Res 2014;66:432-9.

23 Zabotti A, McGonagle DG, Giovannini I, et al. Transition phase towards psoriatic arthritis: clinical and ultrasonographic characterisation of psoriatic arthralgia. $R M D$ Open 2019;5:e001067.

24 Bandinelli F, Milla M, Genise S, et al. Ultrasound discloses entheseal involvement in inactive and low active inflammatory bowel disease without clinical signs and symptoms of spondyloarthropathy. Rheumatology 2011;50:1275-9.

25 Coates LC, Kavanaugh A, Mease PJ, et al. Group for research and assessment of psoriasis and psoriatic arthritis 2015 treatment recommendations for psoriatic arthritis. Arthritis Rheumatol 2016;68:1060-71.

26 Mease P, Sieper J, Van den Bosch F, et al. Randomized controlled trial of adalimumab in patients with nonpsoriatic peripheral spondyloarthritis. Arthritis Rheumatol 2015;67:914-23.

27 McGonagle D, Mclnnes IB, Deodhar A, et al. Resolution of enthesitis by guselkumab and relationships to disease burden: 1-year results of two phase 3 psoriatic arthritis studies. Rheumatology 2021;60:5337-50.

28 Buskila D, Odes LR, Neumann L, et al. Fibromyalgia in inflammatory bowel disease. J Rheumatol 1999;26:1167-71.

29 Reveille JD. Hla-B27 and the seronegative spondyloarthropathies. Am J Med Sci 1998;316:239-49.

30 Reveille JD. Genetics of spondyloarthritis--beyond the MHC. Nat Rev Rheumatol 2012;8:296-304.

31 Cypers H, Varkas G, Beeckman S, et al. Elevated calprotectin levels reveal bowel inflammation in spondyloarthritis. Ann Rheum Dis 2016;75:1357-62.

32 Harbord M, Annese V, Vavricka SR, et al. The first European evidence-based consensus on extra-intestinal manifestations in inflammatory bowel disease. J Crohns Colitis 2016;10:239-54.

33 Al-Jarallah K, Shehab D, Al-Attiyah R, et al. Antibodies to mutated citrullinated vimentin and anti-cyclic citrullinated peptide antibodies in inflammatory bowel disease and related arthritis. Inflamm Bowel Dis 2012;18:1655-62.

34 Al-Jarallah K, Shehab D, Al-Azmi W, et al. Rheumatic complications of inflammatory bowel disease among Arabs: a hospital-based study in Kuwait. Int J Rheum Dis 2013;16:134-8.

35 Bandinelli F, Terenzi R, Giovannini L, et al. Occult radiological sacroiliac abnormalities in patients with inflammatory bowel disease who do not present signs or symptoms of axial spondylitis. Clin Exp Rheumatol 2014:32:949-52.
36 Bandyopadhyay D, Bandyopadhyay S, Ghosh P, et al. Extraintestinal manifestations in inflammatory bowel disease: prevalence and predictors in Indian patients. Indian J Gastroenterol 2015;34:387-94.

37 Barreiro-de Acosta M, Domínguez-Muñoz JE, Núñez-Pardo de Vera $\mathrm{MC}$, et al. Relationship between clinical features of Crohn's disease and the risk of developing extraintestinal manifestations. Eur $J$ Gastroenterol Hepatol 2007;19:73-8.

38 Bertolini E, Macchioni P, Rizzello F, et al. Ultrasonographic and clinical assessment of peripheral enthesitis and arthritis in an Italian cohort of inflammatory bowel disease patients. Semin Arthritis Rheum 2020 ;50:436-43. 06;

39 Beslek A, Onen F, Birlik M, et al. Prevalence of spondyloarthritis in Turkish patients with inflammatory bowel disease. Rheumatol Int 2009;29:955-7.

40 Christodoulou DK, Katsanos KH, Kitsanou M, et al. Frequency of extraintestinal manifestations in patients with inflammatory bowel disease in northwest Greece and review of the literature. Dig Liver Dis 2002;34:781-6.

41 D'Incà R, Podswiadek M, Ferronato A, et al. Articular manifestations in inflammatory bowel disease patients: a prospective study. Dig Liver Dis 2009;41:565-9.

42 de Vlam K, Mielants H, Cuvelier C, et al. Spondyloarthropathy is underestimated in inflammatory bowel disease: prevalence and HLA association. J Rheumatol 2000;27:2860-5.

43 Ditisheim S, Fournier N, Juillerat P, et al. Inflammatory articular disease in patients with inflammatory bowel disease: result of the Swiss IBD cohort study. Inflamm Bowel Dis 2015;21:2598-604.

44 Dmowska-Chalaba J, Kontny E. Inflammatory bowel diseaserelated arthritis - clinical evaluation and possible role of cytokines. Reumatologia 2015;53:236-42.

45 Duricova D, Leroyer A, Savoye G, et al. Extra-Intestinal manifestations at diagnosis in Paediatric- and Elderlyonset ulcerative colitis are associated with a more severe disease outcome: a population-based study. J Crohns Colitis 2017;11:1326-34.

46 Fatemi A, Jazi HH, Emami MH, et al. Relationship between articular and nonarticular manifestations in inflammatory bowel diseases. $J$ Res Med Sci 2016;21:48.

47 Gotler J, Amitai MM, Lidar M, et al. Utilizing Mr enterography for detection of sacroiliitis in patients with inflammatory bowel disease. J Magn Reson Imaging 2015;42:121-7.

48 Hammoudeh M, Elsayed E, Al-Kaabi S, et al. Rheumatic manifestations of inflammatory bowel diseases: a study from the middle East. J Int Med Res 2018;46:3837-47.

49 Hiller A, Biedermann L, Fournier N, et al. The appearance of joint manifestations in the Swiss inflammatory bowel disease cohort. PLoS One 2019;14:e0211554

50 Isene R, Bernklev T, Høie O, et al. Extraintestinal manifestations in Crohn's disease and ulcerative colitis: results from a prospective, population-based European inception cohort. Scand J Gastroenterol 2015;50:300-5

51 Kamo K, Shuto T, Haraguchi A. Prevalence of spondyloarthritis symptom in inflammatory bowel disease patients: a questionnaire survey. Mod Rheumatol 2015;25:435-7.

52 Karmiris K, Avgerinos A, Tavernaraki A, et al. Prevalence and characteristics of extra-intestinal manifestations in a large cohort of Greek patients with inflammatory bowel disease. J Crohns Colitis 2016;10:429-36

53 Lakatos L, Pandur T, David G, et al. Association of extraintestinal manifestations of inflammatory bowel disease in a Province of Western Hungary with disease phenotype: results of a 25-year follow-up study. World J Gastroenterol 2003;9:2300-7.

54 Lanna CCD, Ferrari MdeLA, Rocha SL, et al. A cross-sectional study of 130 Brazilian patients with Crohn's disease and ulcerative colitis: analysis of articular and ophthalmologic manifestations. Clin Rheumatol 2008;27:503-9.

55 Luchetti MM, Benfaremo D, Bendia E, et al. Clinical and patient reported outcomes of the multidisciplinary management in patients with inflammatory bowel disease-associated spondyloarthritis. Eur $J$ Intern Med 2019;64:76-84.

56 Mocelin V, Nisihara RM, Utiyama SRR, et al. Anti-CCP antibodies and Rheumatological findings in Brazilian patients with Crohn's disease. Digestion 2015;91:303-6.

57 Orchard TR, Holt H, Bradbury L, et al. The prevalence, clinical features and association of HLA-B27 in sacroiliitis associated with established Crohn's disease. Aliment Pharmacol Ther 2009;29:193-7.

58 Peeters H, Vander Cruyssen B, Mielants H, et al. Clinical and genetic factors associated with sacroiliitis in Crohn's disease. $J$ Gastroenterol Hepatol 2008;23:132-7. 
59 Picchianti-Diamanti A, Lorenzetti R, Chimenti MS, et al. Enteropathic spondyloarthritis: results from a large nationwide database analysis. Autoimmun Rev 2020;19:102457.

60 Pokharna RK, Kabra PK, Sharma R, et al. Extraintestinal manifestations of idiopathic ulcerative colitis in northwestern India. Indian J Gastroenterol 2004;23:89-90.

61 Queiro R, Maiz O, Intxausti J, et al. Subclinical sacroiliitis in inflammatory bowel disease: a clinical and follow-up study. Clin Rheumatol 2000;19:445-9.

62 Ricart E, Panaccione R, Loftus EV, et al. Autoimmune disorders and extraintestinal manifestations in first-degree familial and sporadic inflammatory bowel disease: a case-control study. Inflamm Bowel Dis 2004;10:207-14

63 Rovisco J, Duarte C, Batticcioto A, et al. Hidden musculoskeletal involvement in inflammatory bowel disease: a multicenter ultrasound study. BMC Musculoskelet Disord 2016;17:84

64 Sahli H, Bachali A, Hamzaoui L, et al. Frequency of axial spondyloarthritis in Tunisian patients with inflammatory bowel diseases. The Egyptian rheumatologist: Elsevier B. V 2018:187-90.

65 Salvarani C, Vlachonikolis IG, van der Heijde DM, et al.

Musculoskeletal manifestations in a population-based cohort of inflammatory bowel disease patients. Scand J Gastroenterol 2001;36:1307-13.

66 Steer S, Jones H, Hibbert J, et al. Low back pain, sacroiliitis, and the relationship with HLA-B27 in Crohn's disease. J Rheumatol 2003;30:518-22.

67 Stolwijk C, Pierik M, Landewé R, et al. Prevalence of self-reported spondyloarthritis features in a cohort of patients with inflammatory bowel disease. Can J Gastroenterol 2013;27:199-205.

68 Subramaniam K, Tymms K, Shadbolt B, et al. Spondyloarthropathy in inflammatory bowel disease patients on TNF inhibitors. Intern Med J 2015;45:1154-60.

69 Turkcapar N, Toruner M, Soykan I, et al. The prevalence of extraintestinal manifestations and HLA association in patients with inflammatory bowel disease. Rheumatol Int 2006;26:663-8.

70 van Erp SJ, Brakenhoff LK, van Gaalen FA, et al. Classifying back pain and peripheral joint complaints in inflammatory bowel disease patients: a prospective longitudinal follow-up study. J Crohns Colitis 2016;10:166-75.

71 Yüksel I, Ataseven H, Bașar O, et al. Peripheral arthritis in the course of inflammatory bowel diseases. Dig Dis Sci 2011;56:183-7. 